\title{
First Cytogenetic Study of Puff-Faced Water Snake, Homalopsis buccata (Squamata, Colubridae) by Conventional Staining, Ag-NOR Banding and GTG-Banding Techniques
}

\author{
Krit Pinthong ${ }^{1}$, Alongklod Tanomtong ${ }^{2 *}$, Nuntaporn Getlekha², \\ Wiwat Sangpadee ${ }^{3}$, Kittiya Sangpakdee ${ }^{4}$, and La-orsri Sanoamuang ${ }^{2}$ \\ ${ }^{1}$ Biology Program, Faculty of Science and Technology, Surindra Rajabhat University, \\ Muang, Surin 32000, Thailand \\ ${ }^{2}$ Applied Taxonomic Research Center (ATRC), Department of Biology, Faculty of Science, \\ Khon Kaen University, Khon Kaen, Muang 40002, Thailand \\ ${ }^{3}$ Biology Program, Faculty of Science, Udon-Thani Rajabhat University, \\ Udon-Thani, Muang 41000, Thailand \\ ${ }^{4}$ College of Bhodivijalaya, Srinakharinwirot University, Wattana, Bangkok 10110, Thailand
}

Received June 19, 2012; accepted February 21, 2013

\begin{abstract}
Summary The first cytogenetics of the puff-faced water snake (Homalopsis buccata) from Khon Kaen Province, Thailand was obtained from the present study. Mitotic chromosome was prepared directly from the spleens of specimens after in vivo colchicines treatment. The metaphase spreads were performed on microscopic slides and air-dried. Conventional staining, Ag-NOR banding, and GTG-banding techniques were applied to stain the chromosome with Giemsa's solution. Results showed that the number of diploid chromosome was $2 n=36$, while the fundamental number (NF) was 52 in both males and females. The types of macrochromosome were four large metacentric, two medium metacentric, six small metacentric, and two small acrocentric chromosome, and 20 microchromosomes. It was found that nucleolar organizer regions (NORs, the representative of chromosome marker) locate on the long arms near centromeres of a pair of microchromosomes, pair 15. The $\mathrm{Z}$ chromosome was a small metacentric chromosome, while the $\mathrm{W}$ chromosome was a small submetacentric chromosome. From the GTG-banding technique, it was found that each chromosome pairs could be clearly differentiated and the numbers of bands in the H. buccata was 109 . The karyotype formula is as follows:
\end{abstract}

$$
2 n(36)=\mathrm{L}_{4}^{\mathrm{m}}+\mathrm{M}_{2}^{\mathrm{m}}+\mathrm{S}_{6}^{\mathrm{m}}+\mathrm{S}_{2}^{\mathrm{a}}+20 \text { microchromosomes }+ \text { sex chromosomes (ZW) }
$$

Key words Puff-faced water snake, Homalopsis buccata, Karyotype, Chromosome.

The snake fauna of Thailand is rich; there are more than 200 species. However, studies on snake karyotypes are very rare. Only a few species have been examined karyologically. The pufffaced water snake, Homalopsis buccata (Linnaeus 1758), is a member of class Reptilia, order Squamata, suborder Serpentes, family Colubridae, and subfamily Homalopsinae (Chan-ard et al. 1999). Colubridae is a family of snakes, and this broad classification of snakes includes about twothirds of all snake species on earth. The earliest species of the snake family date back to the Oligocene epoch. With 304 genera and 1,938 species, Colubridae is the largest snake family. Colubrid species are found on every continent except Antarctica (Bauer et al. 1998). The Colubridae are not a natural group, as many are more closely related to other groups (Lawson et al. 2005).

\footnotetext{
* Corresponding author, e-mail: tanomtong@hotmail.com

DOI: $10.1508 /$ cytologia. 78.141
} 
The genus Homalopsis can be distinguished from all other Southeast Asian snakes. Visual characteristics of $H$. buccata are: dark brown upper surface, with narrow, pale brown, black-edged transverse bands, which are yellow in young specimens; head pale with a triangular or V-shaped dark marking on the snout, an A-shaped spot on the occiput, and a dark band on each side passing through the eye and extending to before the eye. The lower surface is white or yellowish, with dark brown spots along each side; the tail has brown spots. The length of the head and body is $820 \mathrm{~mm}$, the tail $230 \mathrm{~mm}$. It eats fish and frogs (Murphy et al. 2012).

Karyological data act as a supplement to the morphological approach. Karyologically, snakes are highly conserved and variation is found only at family or subfamily level. They show a narrow range of chromosome numbers showing a preponderance of species with $2 n=36$ including 16 macrochromosomes and 20 microchromosomes (Sharma and Kour 2005). Reptilian chromosomes have long been under discussion, particularly in relation to the sex determining mechanism, because in reptiles the situation is inconsistent showing female heterogamety in many species of snakes (Kobel 1967, Beçak et al. 1962, 1964, Singh 1972).

From a literature review about cytogenetic studies of snakes in the family Colubridae, covering reports by Nakamura (1927, 1928, 1935), Matthey (1931), Bhatnager (1959), Beçak (1965), Kobel (1967), Fischman et al. (1968), Beçak and Beçak (1969), Bury et al. (1970), Dutt (1970), Gorman and Gress (1970), Singh et al. (1970), Baker et al. (1972), Singh (1972), Gutiérrez et al. (1984), Moreno et al. (1987), Ota and Iwanaga (1996), Ota (1999), Beçak et al. (2003) and Aprea et al. (2003). The present cytogenetic study, the report on karyotype analysis and chromosomal characteristic of the nucleolar organizer regions (NORs) of H. uccata, is the first record. In the future, basic knowledge on and the cytogenetics of $H$. buccata could be applied to several areas of research and in particular for protection from extinction.

Materials and methods

Two adult males and females of $H$. buccata (family Colubridae) were captured in the field from Khon Kaen province, Thailand. Chromosome preparation was conducted by squash technique, from spleens. Conventional staining, Ag-NOR banding (Howell and Black 1980) and GTGbanding techniques (Rooney 2001) were applied to stain the chromosomes with Giemsa's solution. The lengths of short arm (Ls) and long arm (Ll) chromosomes were measured and calculated for the length of total arm chromosome (LT, LT=Ls+Ll). Relative length (RL) and centromeric index (CI) were estimated. CI was also computed to classify the types of chromosomes according to Chaiyasut (1989). All parameters were used in karyotyping and idiograming.

\section{Results and discussion}

Karyotype analysis and morphometric measurements of the chromosomes of $H$. buccata have been conducted. An analysis of 50 well-spread metaphase plates from different somatic tissue of two male and two female specimens revealed a diploid chromosome count of $2 n=36$ comprising 16 macrochromosomes and 20 microchromosomes (Fig. 1). The macrochromosomes include four large metacentric, two medium metacentric, six small metacentric, two small acrocentric, and two sex chromosomes (ZW system). The Z chromosome is the small metacentric chromosome, while the $\mathrm{W}$ chromosome is a small submetacentric chromosome.

There exists a shape distinction in size between macrochromosomes and microchromosomes; all the microchromosomes are very small, dot-like with a size ranging from 1.0 to 0.4 microns. The sex chromosomes could be distinguished in either sex. Only one nucleolar organizer region site was detected in the silver-stained cells (Ag-NOR banding technique) analyzed; this site locates only on the centromere of the long arm of the telocentric microchromosome pair 15 (Fig. 3). Very little is 

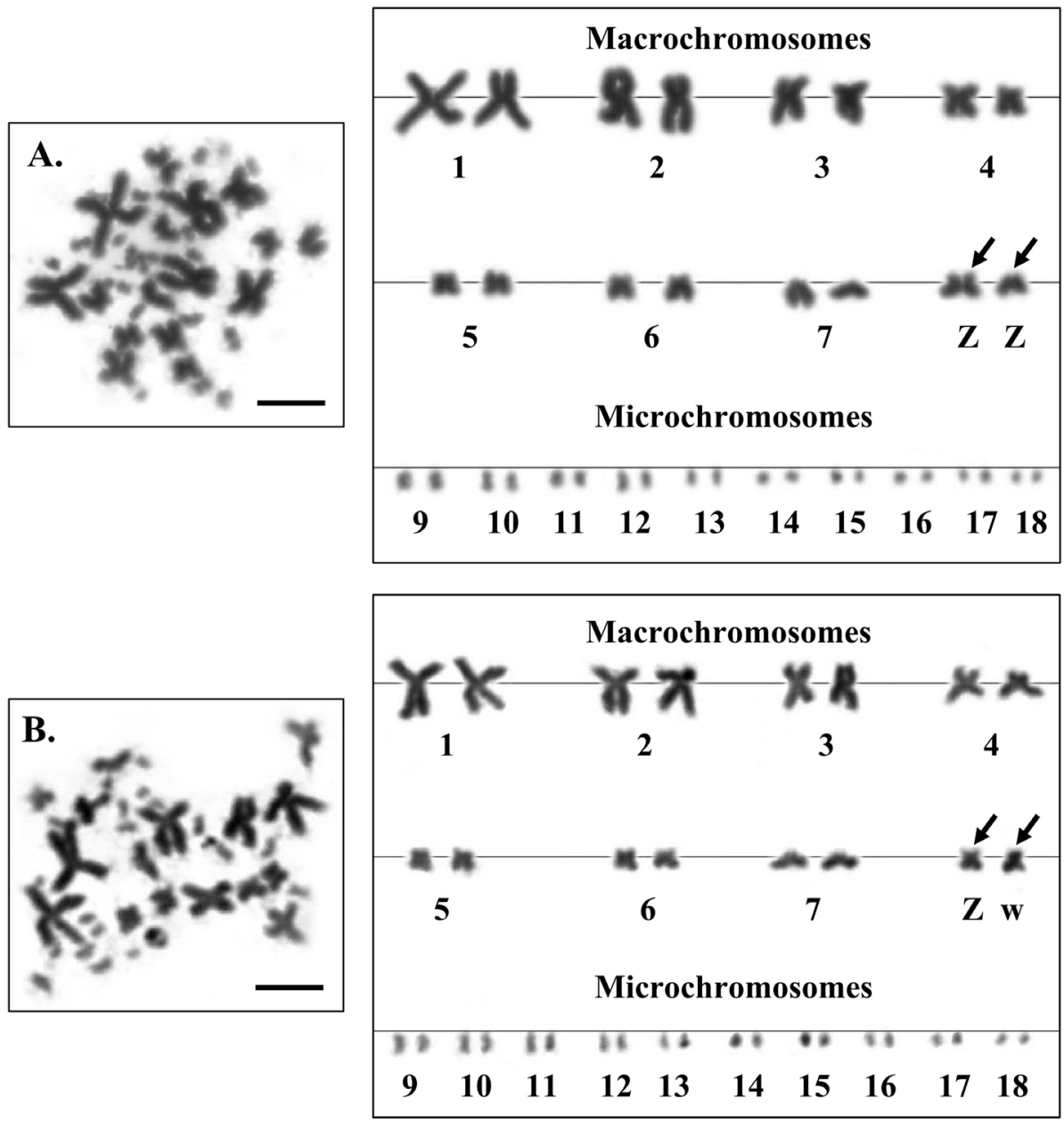

Fig. 1. Metaphase chromosome plates and karyotypes of male (A) and female (B) puff-faced water snake (Homalopsis buccata), $2 n=36$, by conventional straining technique. The arrows indicate sexmacrochromosomes pair 8 (scale bars $10 \mu \mathrm{m})$.

known about NORs in snakes. In some snakes, e.g., Bothrops insularis, B. jararacussu (Beçak et al. 1990), Elephe taeniura (Wang et al. 1991), E. rofudorsata (Guo et al. 1992), the NORs are distributed on the microchromosomes. But in others, e.g., Macropisthodon rudis, NORs are distributed on the macrochromosomes (Toriba 1990, Ruifang et al. 1996). This polymorphism may have been created by chromosomal rearrangement. Toriba (1990) and Wang et al. (1991) also proposed that in adults, the NORs are abrupt, but in juveniles, they are often clear. This phenomenon was interpreted as a higher synthesis rate in juveniles which is needed cytologically (Toriba 1990). In the present study, the NORs were detectable in adults.

The GTG-banding technique on $H$. buccata revealed that the number of bands on one set of haploid chromosomes, which includes 34 autosomes (14 macrochromosomes and 20 microchromosomes) and the $\mathrm{Z}$ and $\mathrm{W}$ chromosomes, is 109 bands (Fig. 5). The GTG-banding technique provides clearly identifiable chromosome bands which are represented by dark band (heterochromatin) and light band (euchromatin) regions on chromosomes. However, some chromosomes cannot be clearly identified because some bands have variation. As above, the chromosome band scoring is represented by the approximate bands that appear. 


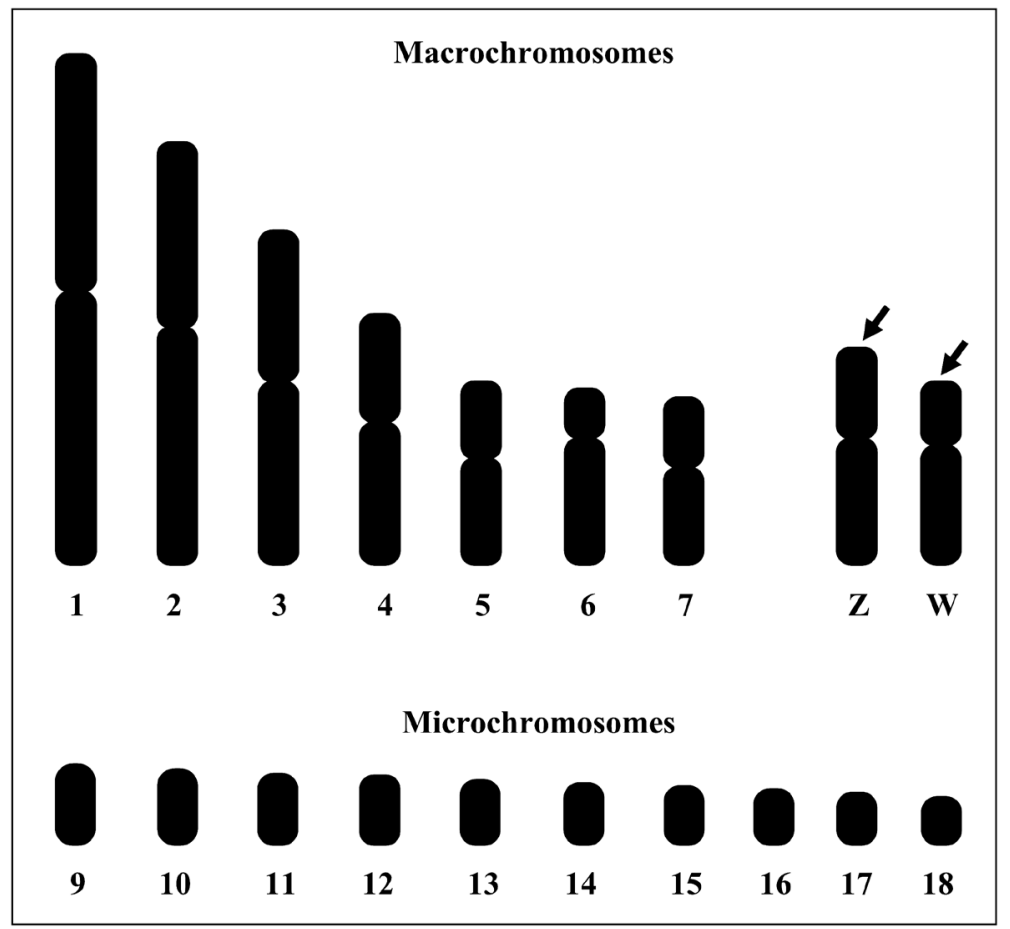

Fig. 2. Idiogram showing lengths and shapes of chromosomes of the puff-faced water snake (Homalopsis buccata), $2 n=36$, by conventional staining technique. The arrow indicates sex-macrochromosomes pair 8.

For the family Colubridae, the $2 n=36$ of H. Buccata which was found here is consistent with the report of Moreno et al. (1987), which showed $2 n=36$ for Philodryas chamissonis. Baker et al. (1972) demonstrated a study on the family Colubridae of northern America, including Arizona elegans, Coluber constrictor, Elaphe guttata, E. obsolete, Heterodon nasicus, Lampropeltis calligaster, L. gelulus, L. mexicana, Maslicophis flagellum, Ma. taeniatus, Natrix erythrogaster, N. harteri, $N$. rhombifera, Phyllorhynchus decurtatus, Pituophis metanoleucus, Salvadora grahamine, S. lineate, Sloreria dekayi, Thamnophis radix, T. couchi, T. cyrlopsis, T. elegans, T. marcianus, T. proximas, T. rufipunctatus and T. sirlalis. It showed that all above species have $2 n=36$, apart from $E$. suboc, which has $2 n=40$.

Moreover, the report of Ota and Iwanaga (1996) indicated that three species of the family Colubridae, namely Amphiesma pryeri, A. concelarum and A. ishigakiense, have $2 n=36$. Singh (1972) demonstrated that Ptyas mucosus has $2 n=34$ while other six species, namely $C$. fasciolatus, $N$. stolata, Lycodon anulicus, Cerberus rhynchops, Boiga forsteni and B. trigonata, have $2 n=36$. In addition, the report of Beçak and Beçak (1969) demonstrated that Hydrodynastes bicinctus and H. gigas have diploid chromosome $2 n=24$, and Clelia occipitolutea has $2 n=50$. According to the comparative discussion described above, we suggest that members of the family Colubridae have a diploid chromosome number of 24 to 50 .

A typical snake karyotype presents as follows: 1) Macrochromosomes and microchromosomes; 2) Diploid chromosome number is $2 n=36$ in almost all of the families studied, normally of the 16 macrochromosomes and 20 microchromosomes type; 3) Ag-NORs and rDNA locate predominantly on microchromosomes; 4) Morphologically differentiated sex chromosomes are of the type ZZ/ZW or not morphologically differentiated in some groups; 5) Heterochromatin (visualized by $\mathrm{C}$-banding technique) is predominantly centromeric or pericentromeric, and telomeric or sub- 

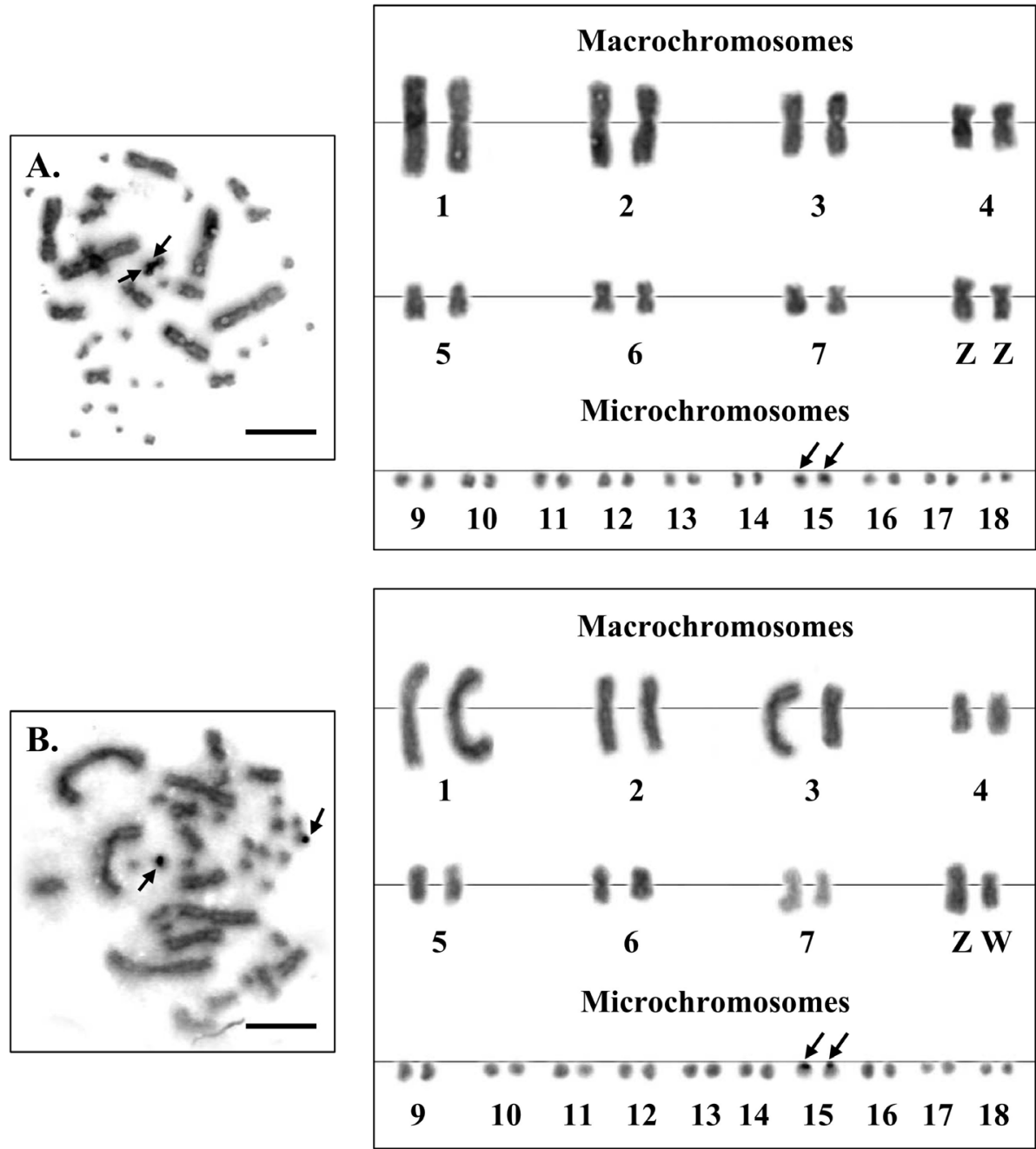

Fig. 3. Metaphase chromosome plates and karyotypes of male (A) and female (B) puff-faced water snake (Homalopsis buccata), $2 n=36$, by Ag-NOR banding technique. The arrows indicate satellite microchromosomes pair 15 (scale bars $10 \mu \mathrm{m}$ ).

telomeric. Interstitial C-bands were seldom reported (Oguiura et al. 2010). While, Beçak et al. (2003) reported that among Colubridae species there is wild variation of chromosome number and different levels of sex chromosome differentiation.

A common feature in Reptilia is the presence of macrochromosomes and microchromosomes, probably due to karyological ancestral derivation from forms that already presented this attribute. The C-banding technique showed that not all microchromosomes are heterochromatic. Moreover, even microchromosomes that are apparently totally heterochromatic may have some euchromatin in them. This condition may be or not advantageous, depending on environmental conditions (Olmo 2005, 2008, Beçak et al. 2003). Hydrodynastes bicinctus bicinctus has $2 n=24$, a very small diploid chromosome number for snakes and no microchromosomes (Beçak and Beçak 1969), which may be interpreted as a formation of favorable linkage groups. This karyotype is clearly a derived one, when other species of the family are analyzed. In the other extreme, the Apostolepis genus presents the highest diploid chromosome number so far found in the suborder Serpentes and the highest number of microchromosomes, some of them very small (Beçak et al. 2003). 


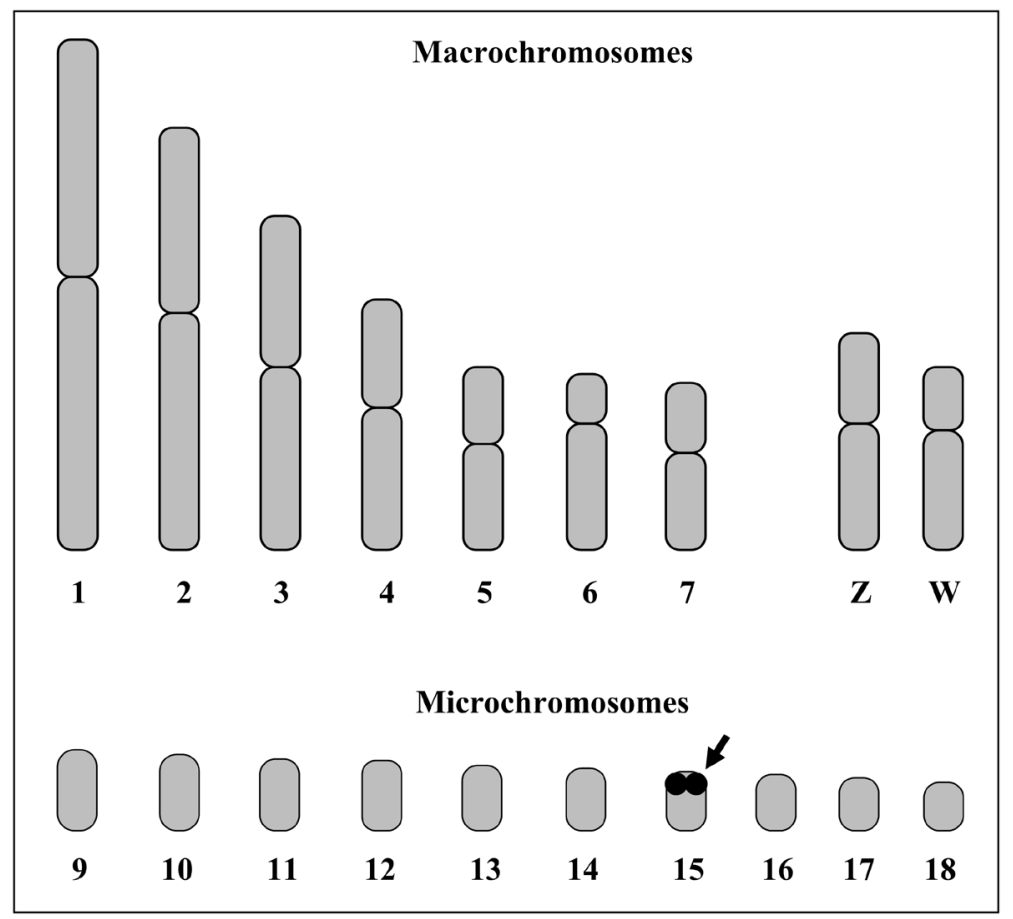

Fig. 4. Idiogram showing satellite microchromosome pair 15 of the puff-faced water snake (Homalopsis buccata), $2 n=36$, by Ag-NOR banding technique. The arrow indicate nucleolar organizer region.

Besides most reptilian orders, microchromosomes are also found in some primitive amphibians, including the families Cryptobranchidae and Hynobiidae, at 2n=56-66 with 14-19 pairs of microchromosomes and most avian (Morescalchi et al. 1977, 1979). Some retiles and all Crocodylia lack microchromosomes (King et al. 1986); a puzzle given that the crocodilian lineage is, phylogenetically, the closest to birds. The genomes of amphibians, retiles, fish and lower chordates do, however, differ from mammals and birds with little or no GC-rice isochore DNA (Holmquist 1989). Microchromosomes and a relatively small genome therefore appear to be characteristic of the common ancestor of terrestrial vertebrates (Burt 2002).

Morphologically differentiated sex chromosomes are spread all over the Metazoa. In vertebrates, they occur in all classes but not in all groups within a class. In non-avian reptiles, they occur in all orders but not homogeneously. In the Colubridae species, different stages of differentiation of the $\mathrm{W}$ chromosome occur: they may differ from the $\mathrm{Z}$ chromosome by the centromere position or by size or by both (Beçak and Beçak 1969, Beçak et al. 1990, Beçak et al. 2003).

The sex chromosomes in the family Colubridae exhibit various states of differentiation. In Pseustes sulphureus sulphureus (Beçak and Beçak 1969) and P. mucosus (Singh 1972), no heteromorphic pair of chromosomes have been observed in either sex. In Coluber fasciolatus, Chironius bicarinatus, Dryadophis bifossatus bifossatus, Drymarchon corais corals, Spilotes pullatus anomalepis and $S$. p. maculatus, there is a heteromorphic pair of sex chromosomes in the females. In these cases, both the $\mathrm{Z}$ and $\mathrm{W}$ chromosomes are almost identical in size but the $\mathrm{Z}$ chromosome has its centromere in the submedian region, whereas in the $\mathrm{W}$ chromosome it is in the subterminal region. The difference in the morphology between the $\mathrm{Z}$ and the $\mathrm{W}$ chromosomes can most simply be explained by the assumption of pericentric inversion. In Elaphe quadrivirgata and E. climacophora, the $\mathrm{W}$ chromosome is slightly smaller than the $\mathrm{Z}$ and it has its centromeres in the terminal and subterminal regions, respectively, whereas in $\mathrm{Z}$ it is in the submedian region. The $\mathrm{Z}$ chromosomes of 

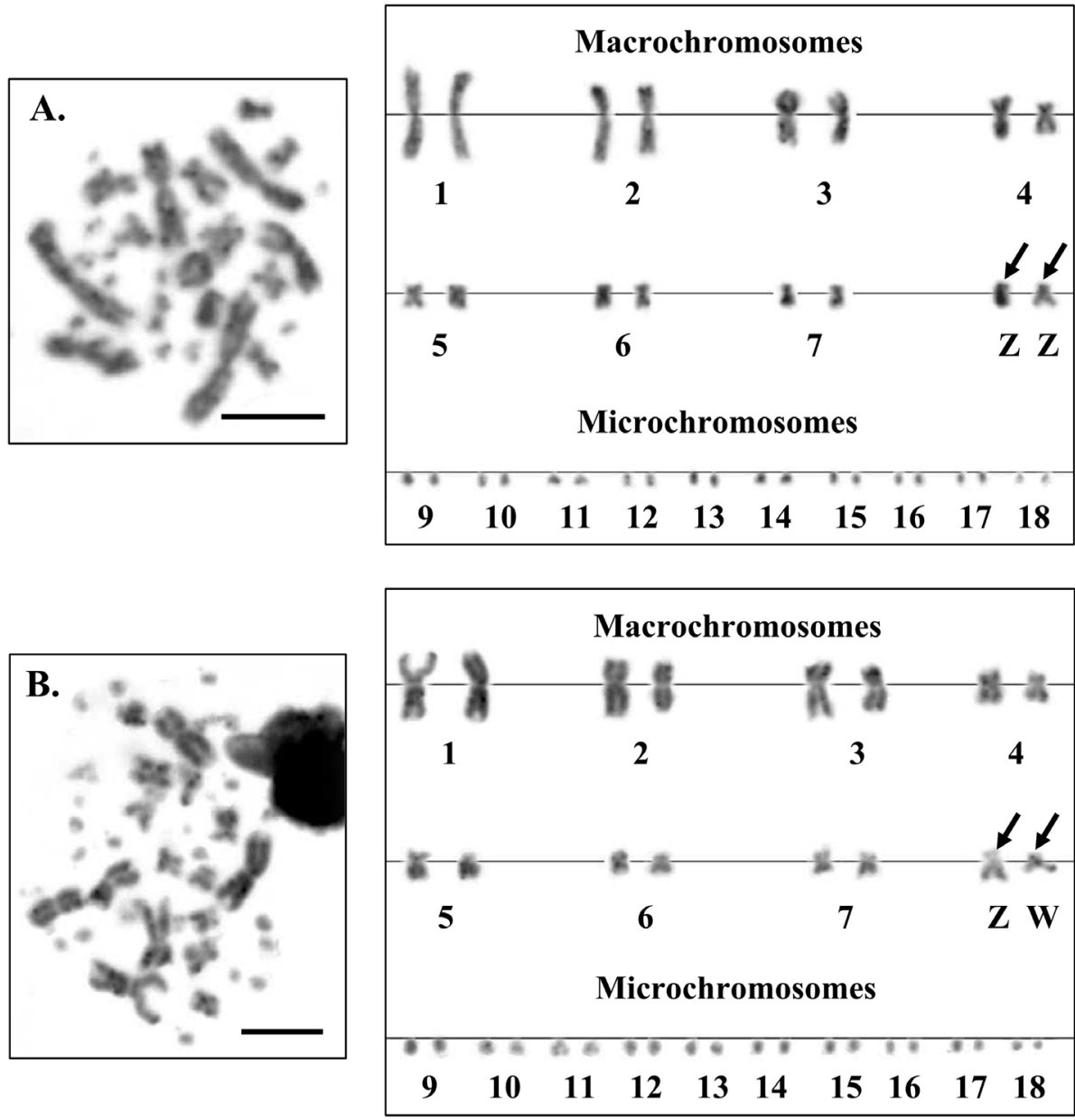

Fig. 5. Metaphase chromosome plates and karyotypes of male (A) and female (B) puff-faced water snake (Homalopsis buccata), $2 n=36$, by GTG-banding technique. The arrows indicate sex-macrochromosomes pair 8 (scale bars $10 \mu \mathrm{m})$.

all the species in this group are more or less of similar size except in C. fasciolatus, E. quadrivirgata and $P$. s. sulphureus which are considerably larger. Similarly, the $\mathrm{W}$ chromosome in C. fasciolatus is the largest amongst all the species (Singh 1972).

The chromosome of mitotic metaphase cells and the karyotypes of $H$. buccata in male and female, as determined by conventional staining, GTG-banding, and Ag-NOR banding techniques, are shown in Fig. 1, 3, and 5, respectively. The chromosomes length of 20 cells (males and females) in mitotic metaphase was measured. The mean length of short arm chromosome (Ls), length of long arm chromosome (Ll), total length of arm chromosome (LT), relative length (RL), centromeric index (CI), size and type of chromosome are presented in Table 1. The idiogram of $H$. buccata shows the gradually decreasing length of the autosomes (Fig. 2, 4, and 6). The H. buccata study revealed that the chromosome marker is the chromosome pair 1, which is the largest metacentric chromosome. The largest and smallest chromosomes show difference in size (approximately 7 folds). The karyotype formula is as follows:

$$
2 n(36)=\mathrm{L}_{4}^{\mathrm{m}}+\mathrm{M}_{2}^{\mathrm{m}}+\mathrm{S}_{6}^{\mathrm{m}}+\mathrm{S}_{2}^{\mathrm{a}}+20 \text { microchromosomes }+ \text { sex chromosomes (ZW) }
$$


Table 1. Mean length of the short arm chromosome (Ls), long arm chromosome (Ll), and total arm chromosome (LT), relative length (RL), centromeric index (CI) and standard deviation (SD) of RL, CI from metaphase chromosomes in 20 cells of the puff-faced water snake (Homalopsis buccata) $2 n=36$.

\begin{tabular}{cccccccc}
\hline \hline $\begin{array}{c}\text { Chromosome } \\
\text { pairs }\end{array}$ & Ls & Ll & LT & RL \pm SD & CI \pm SD & $\begin{array}{c}\text { Chromosome } \\
\text { sizes }\end{array}$ & $\begin{array}{c}\text { Chromosome } \\
\text { types }\end{array}$ \\
\hline 1 & 158.05 & 181.66 & 339.71 & $0.209 \pm 0.020$ & $0.535 \pm 0.031$ & Large & Metacentric \\
2 & 123.94 & 157.82 & 281.75 & $0.173 \pm 0.011$ & $0.560 \pm 0.030$ & Large & Metacentric \\
3 & 100.71 & 121.81 & 222.53 & $0.137 \pm 0.013$ & $0.547 \pm 0.037$ & Medium & Metacentric \\
4 & 72.73 & 94.20 & 166.93 & $0.103 \pm 0.013$ & $0.564 \pm 0.043$ & Small & Metacentric \\
5 & 51.64 & 70.34 & 121.98 & $0.075 \pm 0.010$ & $0.577 \pm 0.042$ & Small & Metacentric \\
6 & 34.16 & 83.56 & 117.72 & $0.072 \pm 0.011$ & $0.710 \pm 0.025$ & Small & Acrocentric \\
7 & 46.20 & 64.77 & 110.97 & $0.068 \pm 0.008$ & $0.584 \pm 0.046$ & Small & Metacentric \\
9 & - & - & 78.18 & $0.126 \pm 0.006$ & - & Microchromosome \\
10 & - & - & 73.19 & $0.118 \pm 0.003$ & - & Microchromosome \\
11 & - & - & 69.91 & $0.113 \pm 0.002$ & - & Microchromosome \\
12 & - & - & 67.47 & $0.109 \pm 0.004$ & - & Microchromosome \\
13 & - & - & 63.23 & $0.102 \pm 0.003$ & - & Microchromosome \\
14 & - & - & 60.24 & $0.097 \pm 0.003$ & - & Microchromosome \\
$15 *$ & - & - & 57.37 & $0.092 \pm 0.004$ & - & Microchromosome \\
16 & - & - & 53.98 & $0.087 \pm 0.003$ & - & Microchromosome \\
17 & - & - & 50.64 & $0.082 \pm 0.005$ & - & Microchromosome \\
18 & - & - & 46.38 & $0.075 \pm 0.004$ & - & Microchromosome \\
$\mathrm{Z}$ & 60.82 & 83.49 & 144.32 & $0.089 \pm 0.018$ & $0.579 \pm 0.049$ & Small \\
$\mathrm{W}$ & 42.30 & 79.70 & 122.00 & $0.075 \pm 0.006$ & $0.653 \pm 0.055$ & Small & Submetacentric \\
& & & & & & &
\end{tabular}

Remark: *=satellite chromosome/NOR.

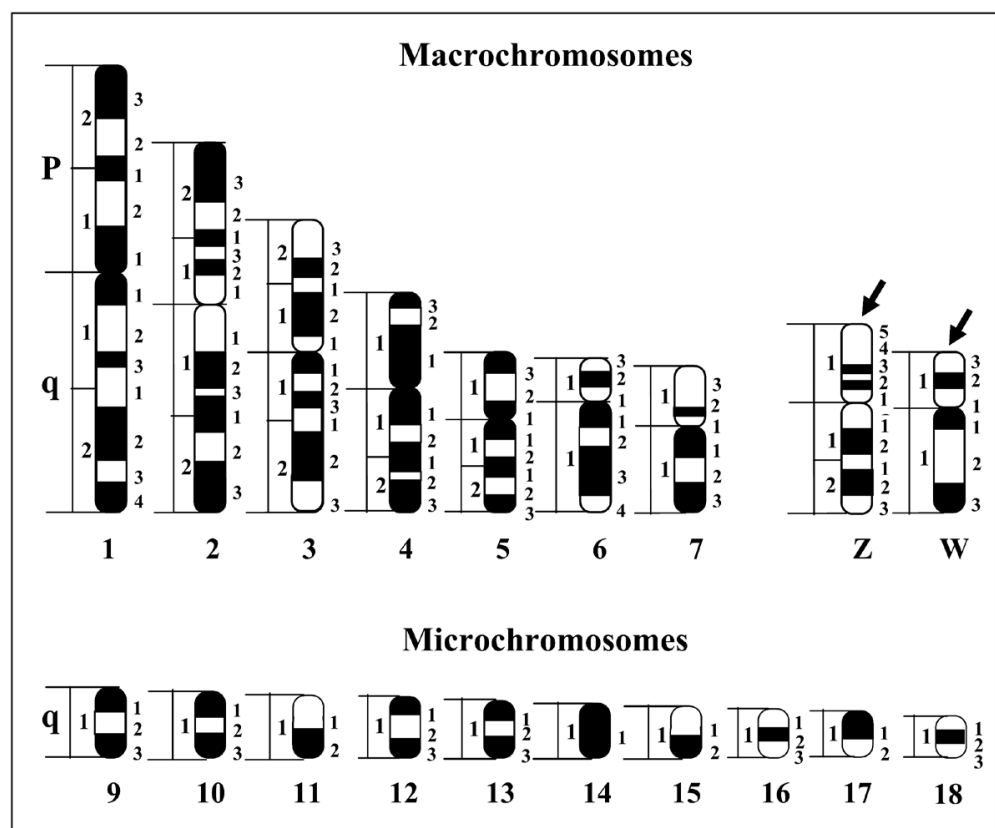

Fig. 6. Idiogram showing lengths and shapes of chromosomes of the puff-faced water snake (Homalopsis buccata), $2 n=36$, by GTG-banding technique. The arrow indicates sex-macrochromosome pair 8 . 


\section{Acknowledgments}

This work was supported by the Applied Taxonomic Research Center (ATRC), Khon Kaen University grant; ATRC-R5304 and by a grant from the Faculty of Science, Khon Kaen University.

\section{References}

Aprea, G., Odierna, G., Andreone, F., Glaw, F., and Vences, M. 2003. Unusual karyotype in the Malagasy colubrid snake Mimophis mahfalensis. Amphib-reptil. 24: 215-219.

Baker, R., Mengden, G., and Bull, J. 1972. Karyotypic studies of thirty-eight species of north American snakes. Copeia 2: $257-265$.

Bauer, A. M., Cogger, H. G., and Zweifel, R. G. 1998. Encyclopedia of reptiles and amphibians. Academic Press, San Diego.

Beçak, W. 1965. Constituicao cromossomica e mecanismo de determinacao do sexo em ofidios sulamericanos. I. Aspectos cariotipicos. Mem Inst Butantan 32: 37-78.

Beçak, W., Rabello-Gay, M. N., Beçak, W., Soma, M., Batistic, R. F., and Trajtengertz, I. 1990. The W chromosome during the evolution and in sex abnormalities of snakes. In: Olmo, E. (ed.). Cytogenetics of amphibians and reptiles. Birkhauser Verlag, Basel. pp. 221-240.

Beçak, W., and Beçak, M. L. 1969. Cytotaxonomy and chromosomal evolution in Serpentes. Cytogenetics 8: $247-262$.

Beçak, W., Beçak, M. L., and Nazirath, H. R. S. 1962. Karyotypic studies of 2 species of south American snakes (Boa constrictor amarali and Bothrops jararaca). Cytogenetics 1: 305-313.

Beçak, W., Beçak, M. L., Nazirath, H. R. S., and Ohno, S. 1964. Close karyological kinship between the reptilian suborder Serpentes and the class Aves. Chromosoma (Berl.). 15: 606-617.

Beçak, W., Beçak, M. L., and Pereira, A. 2003. Somatic pairing endomitosis and chromosome aberrations in snakes (Viperidae and Colubridae). Annals of the Brazilian Academy of Science 75: 285-300.

Bhatnagar, A. N. 1959. Studies on the structure and behaviour of chromosomes of Oligodon arnensis Shaw (Colubridae: Ophidia). Cytologia 24: 459-465.

Burt, D. W. 2002. Origin and evolution of avian microchromosomes. Cytogenet. Genome Res. 96: 97-112.

Bury, R. B., Gress, F., and Gorman, G. 1970. Karyotypic survey of some colubrid snakes from western north America. Herpetologica 26: 461-466.

Chaiyasut, K. 1989. Cytogenetics and Cytotaxonomy of the Family Zephyranthes. Department of Botany, Faculty of Science, Chulalongkorn University, Bangkok.

Chan-ard, T., Grossmann, W., Gumprecht, A., and Schulz, K. D. 1999. Amphibians and reptiles of peninsular Malaysia and Thailand. Bushmaster Publications, Würselen.

Gorman, G. C., and Gress, F. 1970. Chromosome cytology of four boid snakes and a varanid lizard, with comments on the cytosystematics of primitive snakes. Herpetologica 26: 308-317.

Dutt, K. 1970. Chromosome variation in two populations of Xenochrophis piscator Sehn. from north and south India (Serpentes, Colubridae). Cytologia 35: 456-464.

Fischman, H. K., Mitra, J., and Dowling, H. 1968. Chromosome analyses of three members of the genus Elaphe (Serpentes). Proceedings of the Annual Meeting of the Genetics Society of America. Genetics Society of America, Austin.

Guo, C. W., Dong, Y. W., and Chen, C. W. 1992. Analysis on karyotype C-banding pattern and Ag-NORs of Elephe rufodorsata. Acta Herpetologica Sinica I, II: 171-174.

Gutiérrez, J. M., Solórzano, A., and Cerdas, L. 1984. Karyotype study of 5 species of Costa Rican snakes of the colubrid family. Rev. Biol. Trop. 32: 263-267.

Holmquist, G. P. 1989. Evolution of chromosome band: molecular ecology of noncoding DNA. J. Mol. Evol. 28: $469-486$.

Howell, W. M., and Black, D. A. 1980. Controlled silver-staining of nucleolus organizer regions with a protective colloidal developer: a 1-step method. Experientia 36: 1014-1015.

King, M., Honcycutt, R., and Contrerca, N. 1986. Chromosomal repatterning in crocodiles: C, G and N-banding and the in situ hybridization of $18 \mathrm{~S}$ and 26S rRNA cistrons. Genetica 70: 191-201.

Kobel, H. R. 1967. Morphometrische karyotypanalyse einiger Schlangenarten. Genetica 38: 1-31.

Lawson, R., Slowinski, J. B., Crother, B. I., and Burbrink, F. T. 2005. Phylogeny of the Colubroidea (Serpentes): New evidence from mitochondrial and nuclear genes. Mol. Phylogenet. Evol. 37: 581-601.

Matthey, R. 1931. Chromosomes de Reptiles, Sauriens, Ophidiens, Cheloniens. L'évolution de la formule chromosomiale chez les Sauriens. Rev. Suisse Zool. 38: 117-186.

Moreno, R., Navarro, J., Iturra, P., and Veloso, A. 1987. The karyotype of Philodryas chamissonis (Colubridae) identification of nucleolar organizer region (NOR) and sex chromosome by banding methods. Rev. Bras. Genet. 
3: 497-506.

Morescalchi, A., Odierna, G., and Olmo, E. 1977. Karyological relationship between the Cyptobranchid salamanders. Speciation 15: 1579 .

Morescalchi, A., Odierna, G., and Olmo, E. 1979. Karyotype of the primitive salamanders, family Hynobiidae. Experientia 35: 1434-1436.

Murphy, J. C., Harold, K., Voris, B. H. C. K., Murthy, J. T., and Cumberbatch, C. 2012. The masked water snakes of the genus Homalopsis Kuhl \& van Hasselt, 1822 (Squamata, Serpentes, Homalopsidae), with the description of a new species. Zootaxa 3208: 1-26.

Nakamura, K. 1927. Preliminary notes on reptilian chromosomes. I. The chromosomes of some snakes. Proc. Imp. Acad. Tokyo 3.

Nakamura, K. 1928. On the chromosomes of a snake (Natrix tigrina). Memoirs of the College of Science, Kyoto Imperial University. B4: 1-8.

Nakamura, K. 1935. Studies on reptilian chromosomes. VI. Chromosomes of some snakes. Memoirs of the College of Science, Kyoto Imperial University. B10: 361-364.

Oguiura, N., Ferrarezzi, H., and Batistic, R. F. 2010. Cytogenetics and molecular data in snakes: A phylogenetic approach. Cytogenet. Genome Res. 127: 128-142.

Olmo, E. 2005. Rate of chromosome changes and replication in reptiles. Genetica 125: 185-203.

Olmo, E. 2008. Trends in the evolution of reptilian chromosomes. Integr. Comp. Biol. 48: 486-493.

Ota, H. 1999. Karyotype of Pareas iwasakii. The first chromosomal description of a Pareatine snake (Colubridae). Japanese Journal of Herpetology 18: 16-18.

Ota, H., and Iwanaga, S. 1996. A systematic review of the snakes allied to Amphiesma pryeri (Squamata: Colubridae) in the Ryukyu Archipelago, Japan. Zool. J. Linn. Soc. 121: 339-360.

Rooney, D. E. 2001. Human Cytogenetics: Constitutional Analysis. Oxford University Press, Oxford.

Ruifang, W., Wanzhao, L., Weishun, H., and Shifang, W. 1996. A study on the karyotype and Ag-NORs of Yunnan Macropisthodon rudis (Reptilia: Colubridae). Zool. Res. 17: 169-172.

Sharma, O. P., and Kour, G. 2005. Karyology of four snakes. Caryologia 58: 380-386.

Singh, L., Sharma, T., and Ray-Chaudhuri, S. P. 1970. Chromosome numbers and sex chromosomes in a few Indian species of amphibia and reptiles. Mammalian Chromosome Newsletter 11: 91-94.

Singh, L. 1972. Evolution of karyotypes in snakes. Chromosoma 38: 185-236.

Toriba, M. 1990. Karyotypes of some species of Japanese colubrid snakes. In: Olmo, E. (ed.). Cytogenetics of amphibians and reptiles. Birkhauser Verlag, Basel. pp. 255-260.

Wang, R. F., He, W. S., and Shi, L. M. 1991. Observations on mitotic chromosomes and synaptonemal complex of Elaphe taeniura (Reptilia). Dong Wu Xue Bao 37: 438-442. 